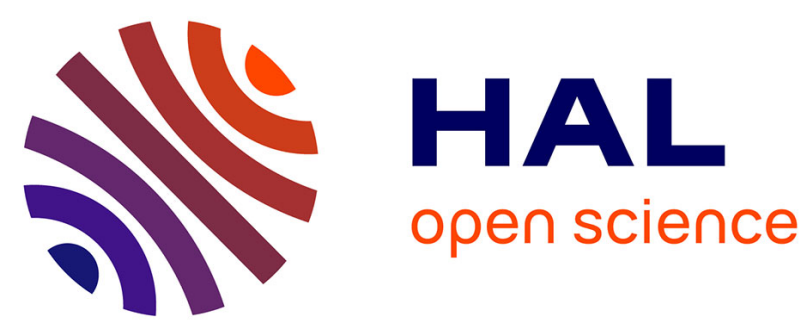

\title{
Real-Time Switches Fault Diagnosis Based on Typical Operating Characteristics of Five-Phase Permanent Magnetic Synchronous Machines
}

\author{
Mohamed Trabelsi, Ngac-Ky Nguyen, Eric Semail
}

\section{To cite this version:}

Mohamed Trabelsi, Ngac-Ky Nguyen, Eric Semail. Real-Time Switches Fault Diagnosis Based on Typical Operating Characteristics of Five-Phase Permanent Magnetic Synchronous Machines. RealTime Switches Fault Diagnosis Based on Typical Operating Characteristics of Five-Phase Permanent Magnetic Synchronous Machines, 2016, pp.1-12. 10.1109/TIE.2016.2554540 hal-01314309

\author{
HAL Id: hal-01314309 \\ https://hal.science/hal-01314309
}

Submitted on 11 May 2016

HAL is a multi-disciplinary open access archive for the deposit and dissemination of scientific research documents, whether they are published or not. The documents may come from teaching and research institutions in France or abroad, or from public or private research centers.
L'archive ouverte pluridisciplinaire HAL, est destinée au dépôt et à la diffusion de documents scientifiques de niveau recherche, publiés ou non, émanant des établissements d'enseignement et de recherche français ou étrangers, des laboratoires publics ou privés. 


\title{
Real-Time Switches Fault Diagnosis Based on Typical Operating Characteristics of Five-Phase Permanent Magnetic Synchronous Machines
}

\author{
Mohamed Trabelsi, Member, IEEE, Ngac Ky Nguyen, Member, IEEE, and Eric Semail, Member IEEE
}

\begin{abstract}
A novel centroid-based diagnostic method of the power switches in five-leg Voltage Source Inverter (VSI) is proposed in this paper. Using a vectorial multi-machine description, a five-phase drive presenting an opened switch or an opened phase faults has typical operating characteristics in comparison to classical three-phase drives. Based on such characteristics, this work aims to provide a simple and robust diagnostic process for switches fault regardless of the shape of the back-EMFs (harmonic components) and the transient states due to the load variation. Original theoretical developments are presented. Experimental results are shown to validate the proposed strategy.
\end{abstract}

Index Terms - AC motor drives, current measurement, diagnosis, fault detection, five-phase permanent magnet synchronous machine, multiphase drive, Voltage Source Inverter (VSI).

\section{NOMENCLATURE}

$\begin{array}{ll}i_{n} & \text { Measured phase currents in abcde frame } \\ i_{\alpha \beta 1} & \text { Stator currents in subspace } \alpha_{1} \beta_{1} \\ i_{\alpha \beta 3} & \text { Stator currents in subspace } \alpha_{3} \beta_{3} \\ \Omega & \text { Mechanical rotor speed } \\ D_{g n} & \text { Centroid angle in } \alpha_{3} \beta_{3} \text { frame } \\ M_{n N} & \text { Average value of the normalized current in } \\ & \alpha_{3} \beta_{3} \text { frame } \\ F_{n-N} & \text { Additional diagnostic variables } \\ \text { PWM } & \text { Pulse-Width Modulation } \\ \text { FDI } & \text { Fault Detection and Isolation } \\ \text { MCSA } & \text { Motor Current Signature Analysis } \\ \text { Back-EMFs } & \text { Back Electromotive Force } \\ \text { OSF } & \text { Open Switch Fault } \\ \text { OPF } & \text { Open Phase Fault } \\ \text { VSI } & \text { Voltage Source Inverter }\end{array}$

\section{INTRODUCTION}

$\mathrm{T}$ HE last decade has witnessed an increasing interest of multiphase drives based on Permanent Magnet Synchronous Motor (PMSM) for aircraft [1], automotive [2][3] and off-shore renewable energy generation [4]-[5] because of their fault-tolerance and high power density. These systems have benefited from the huge development of electronic components for their control and supply [6]-[7]. Complex Real-Time controls can be now achieved thanks to FPGA
(Field Programmable Gate Array) and DSP (Digital Signal Processor) even in fault-mode configuration [8]-[11].

Even if the multiphase drives are intrinsically fault-tolerant to an opened switch fault or an opened phase fault since a rotating field can be generated, the impact of the fault must be carefully studied in terms of oversizing, induced torque ripples and vibrations that can lead to secondary faults in the other parts of the system [12].

In previously published statistical studies [13], the percentage of faults for three-phase variable-speed drives was evaluated to about $60 \%$ due to the user's experiences during the first year of operation. In addition, $70 \%$ of these faults were related to power switches of the VSI, such as shortcircuit fault and open-circuit fault.

Moreover, the considered systems in the paper (aircraft, automotive, ship and offshore turbine) are exposed, in addition to the natural aging process, to hard environmental conditions inducing faults essentially related to the machines or inverters. These faults can lead to unpredicted downtime, since the drive has to be stopped for emergency or for non-programmed maintenance schedule.

In this context, to improve the functional reliability and availability of such systems, several fault-tolerant strategies have been investigated, as proposed in [14]-[19]. However, their implementation requires first and foremost the right information provided by diagnostic steps that will be used to introduce an appropriate reconfiguration of control of the drive. The reconfiguration of control strategy keeps a functioning of the drive as normal as possible until a maintenance is scheduled. Hence, the sequence including fault detection, identification and isolation is necessary and its duration also has to be considered.

The impact of a short-circuit fault is usually destructive with classical star-coupled drives and needs either special VSI with two transistors in series or with supplementary components such as triac or special architecture such as openwindings drives [18]. It is the reason why only opened switch or opened phase faults will be considered in this paper without any additional power component in comparison with normal operating conditions.

Evaluation of the existing strategies, for the three-phase systems, has been addressed in [12] before 2009 and recently in [8] and [20]. They can be classified as model based methods [21] or signal based methods.

The first ones need an accurate system model to achieve a robust algorithm. Techniques based on signals analysis require 
the measurement of the inverter's output (currents or voltages).

Methods based on voltage analysis are addressed in [22][24]. The fault occurrence is detected by analyzing the error between the measured and estimated pole-voltages, by monitoring the voltages endured by the lower switches, or by combining the reference of switching signals and the inverter output voltages. However, the major drawback of these methods is that an extra hardware or extra sensors are needed for real time strategies implementation.

Techniques based on line currents or its variants have been reported in [25]-[30]. In [25], the authors suggested the normalized DC current method. An improved version of this technique has been proposed and consists in using fuzzy logic symptoms, as in [26]. However, a drawback of this method consists in the closed-loop control scheme where there is a DC component which is added to the healthy phase and leads to the sensitivity of the proposed method to false alarms. In [29], the fault detection scheme is achieved based on the operating characteristics of the BLDC motor. Other techniques, based on discrete wavelet transform and fuzzy logic, have been investigated in [28]. However, these methods require a relatively long diagnostic time for the classical three-phase drive and they need even longer detection time for the multiphase system. Others FDIs (Fault Detection and Isolation) based on the calculation of the error between actual and reference phase current quantities have been proposed in [20] and [29], and were extended to the multiple-fault occurrence in power switches. However, these techniques are limited only to the conventional systems with balanced three phase currents and sinusoidal EMFs of PMSM drives. In fact, while working with multiphase PMSM drives, usually the EMFs can contain multiple harmonic components such as third, fifth, seventh and ninth harmonics. As a consequence, the output inverter current can be distorted with the same components, according to the used control strategy, resulting thus in false alarms when applying the conventional FDI strategies.

Contrariwise, there are only a few works which addresses specifically the FDI problem for multiphase systems especially under inverter switch faults. The work done in [30] addresses the FDI process for multiphase electric drives using an approach based on particular properties of multiphase machines belong several characteristics in $(\mathrm{dq})$ frames in comparison with three-phase machine. Indeed, in [30], the FDI algorithm is based on an adaptive model identification of the phase currents in order to detect an open switch fault or an open phase fault. As the reference model is obtained by numerical calculus, time to achieve identification and adaptation of the model can be important. The reference currents are estimated thanks to a RLS (Recursive Least Squares) filter of which the computational response time is depending on the necessary time to obtain the convergence of the filter. As a consequence this method could impose constraints on the capacities of the processor, especially at high speeds when the sampling period is weak.

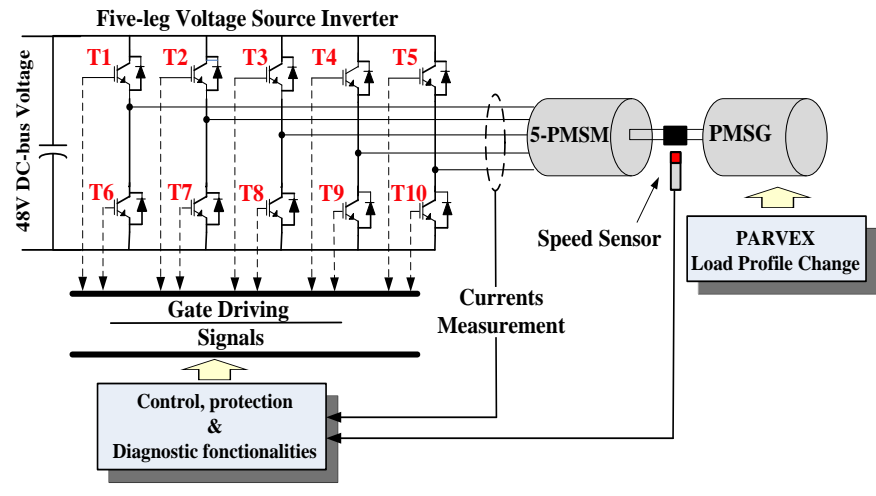

Fig. 1. Standard five-phase electric drive.

The proposed method described in the paper is based on a feature associated with the multiphase machines: the fact that it is existing at least one plane (called Ps and associated to the third harmonics of electrical variables) in normal mode where the amplitude of currents is low (weak or zero currents depending on the value of the third harmonic component of electromotive forces). In this Ps plane, the modification of the currents due to an open switch fault is more important in percentage than the corresponding variation in the $\mathrm{P}_{\mathrm{m}}$ plane associated in normal mode with the first harmonic which is the origin of the most part of the torque. So it can be expected that a method based on the scan of this non-principal $P_{s}$ plane will be sensitive to fault even without precise identification of the system. Indeed, when a fault happens, the projection of the first harmonics of currents in the Ps is no more equal to zero because the phase currents are asymmetrical.

As a consequence, this important variation leads to a fast detection. Moreover, as in normal mode the projection of the first harmonics of the currents in the chosen $\mathrm{P}_{\mathrm{s}}$ plane is equal to zero, the method should be naturally robust to fast transients of currents during for example acceleration and load change. With the same idea the variation of any parameter (resistance, inductance, back-EMF due to temperature) of the PMSM has a weak effect on the FDI process because of zero values projection of the back-EMFs, the currents and the voltages into the Ps.

The paper is organized as follows. Section II details the post-fault operation of the five-phase and the fundamental theory quantifying the non-zero fault profiles reflected in the two decoupled $\alpha \beta$-frames. The proposed FDI is detailed in section III, with a mathematical development on the phase currents normalization and the calculation of the reference directions in $\alpha_{3} \beta_{3}$ frame which gives clear indication of the fault occurrence. Conclusions and remarks are finally provided in the last section.

\section{PMSM POST-FAULT OPERATING CHARACTERISTICS}

\section{A. Structure of the Five-Phase PMSM and the VSI}

A simplified diagram of the considered electric drive is illustrated in Fig. 1. This structure comprises a five-phase PMSM, a VSI, a variable load generated through an industrial electrical motion drive and a control system which includes the protection and diagnostic functionalities. The VSI consists 
of the parallel connection of five-leg inverter. It uses a constant voltage source provided by an isolated DC-source and a capacitive DC-link. Each leg is composed of two MOSFET transistors $\left(\mathrm{T}_{\mathrm{K}}, \mathrm{T}_{\mathrm{K}+5}, \mathrm{k}=1,2,3,4,5\right)$ with antiparallel freewheeling diodes $\left(\mathrm{D}_{\mathrm{K}}, \mathrm{D}_{\mathrm{K}+5}\right)$ used to provide a negative current path through the switches.

The output currents of the VSI can be expressed as follows:

$$
i_{n}(t)=\sum_{h=1}^{\infty} I^{h} \sin \left(h\left(p \Omega t-(n-1) \frac{2 \pi}{5}\right)\right)
$$

where, $n=1, \ldots, 5$ represents the phase current $\left(i_{a}, i_{b}, i_{c}, i_{d}\right.$, and $\left.i_{e}\right), h$ is the order of the current harmonics, $I^{h}$ is the magnitude of the $h^{\text {th }}$ current harmonic, and $p \Omega$ is the electrical fundamental frequency.

For the PMSM under study, it is assumed that the electromagnetic torque is produced by the low order harmonic components. However, only the first and the third harmonics are considered in this paper. As a result, equation (1) can be rewritten, for a healthy condition, as follows:

$$
i_{n}(t)=I^{h 1} \sin \left(p \Omega t-(n-1) \frac{2 \pi}{5}\right)+I^{h 3} \sin \left(3\left(p \Omega t-(n-1) \frac{2 \pi}{5}\right)\right)
$$

The current signals, in the decoupled subspaces, are obtained by applying the Concordia transformation:

$$
\left[i_{\alpha \beta}\right]_{\text {Concordia }}=\sqrt{\frac{2}{5}}[C]\left[i_{n}(t)\right]
$$

with

$$
[C]=\left[\begin{array}{ccccc}
\frac{1}{\sqrt{2}} & \frac{1}{\sqrt{2}} & \frac{1}{\sqrt{2}} & \frac{1}{\sqrt{2}} & \frac{1}{\sqrt{2}} \\
1 & \cos \frac{2 \pi}{5} & \cos \frac{4 \pi}{5} & \cos \frac{6 \pi}{5} & \cos \frac{8 \pi}{5} \\
0 & \sin \frac{2 \pi}{5} & \sin \frac{4 \pi}{5} & \sin \frac{6 \pi}{5} & \sin \frac{8 \pi}{5} \\
1 & \cos \frac{4 \pi}{5} & \cos \frac{8 \pi}{5} & \cos \frac{12 \pi}{5} & \cos \frac{16 \pi}{5} \\
0 & \sin \frac{4 \pi}{5} & \sin \frac{8 \pi}{5} & \sin \frac{12 \pi}{5} & \sin \frac{16 \pi}{5}
\end{array}\right]
$$

This transformation leads to three subspaces associated to three fictitious machines which are called zero-sequence machine (ZSM), main machine (MM) and secondary machine (SM), respectively. More details about the subspace vector theory are given in [9]. Because of the star connection without neutral of the PMSM, there is no path for the zero-sequence current. In healthy operation, the first two-dimensional subspace $\alpha_{1} \beta_{1}$ is associated with the first harmonic electrical components (voltage, current, back-EMF) corresponding to the MM. The second subspace $\alpha_{3} \beta_{3}$ corresponds to the SM. It is associated in healthy operation to the third harmonic components.
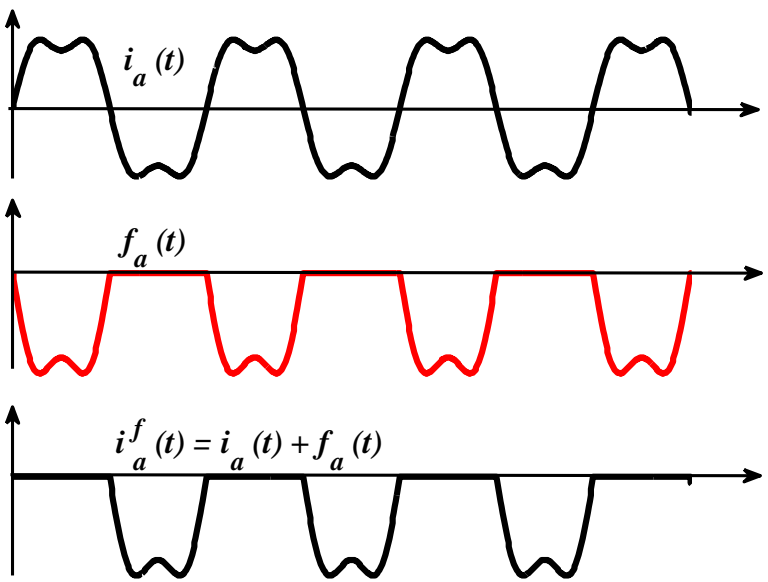

Fig. 2. Phase current profile under fault condition: open-circuit in the upper switch of phase a (T1).

TABLE I

FAULT PROFILE ACCORDING TO THE FAULTY SWITCHES

\begin{tabular}{|c|c|c|c|c|c|c|c|c|c|c|}
\hline $\begin{array}{c}\text { Fault } \\
\text { quantities }\end{array}$ & T1 & T6 & T2 & T7 & T3 & T8 & T4 & T9 & T5 & T10 \\
\hline$f \mathbf{a}$ & $\leq \mathbf{0}$ & $\mathbf{0}$ & & & & & & & & \\
\hline$f \mathbf{b}$ & & & $\leq \mathbf{0}$ & $\mathbf{2 0}$ & & & & & & \\
\hline$f c$ & & & & & $\leq \mathbf{0}$ & $\geq \mathbf{0}$ & & & & \\
\hline$f d$ & & & & & & & $\leq 0$ & $\geq \mathbf{0}$ & & \\
\hline$f \mathrm{e}$ & & & & & & & & & $\leq 0$ & $\geq \mathbf{0}$ \\
\hline
\end{tabular}

For a healthy condition, the inverter output currents in Concordia frame are:

$$
i_{\alpha \beta 1}(t)=\left\{\begin{array}{l}
\sqrt{\frac{5}{2}} I^{h 1} \sin (p \Omega t) \\
\sqrt{\frac{5}{2}} I^{h 1} \sin \left(p \Omega t+\frac{\pi}{2}\right)
\end{array}\right.
$$

for the first harmonic, and

$$
i_{\alpha \beta 3}(t)=\left\{\begin{array}{l}
\sqrt{\frac{5}{2}} I^{h 3} \sin (3 p \Omega t) \\
\sqrt{\frac{5}{2} I^{h 3} \sin \left(3\left(p \Omega t+\frac{\pi}{2}\right)\right)}
\end{array}\right.
$$

for the third harmonic.

\section{B. Fault Profile Modeling in PWM-VSI}

After the occurrence of an open switch fault, the faulty phase current will be limited to flow only in the negative or positive direction according to the affected power switch, and consequently, alternative waveforms cannot be shaped. As the PMSM is fed by five-leg inverter, five possible open-circuit faults can be visualized according to each motor phase current. However, it is possible to model them by using an additive representation of the faulty currents $\left(i_{a}^{f}, i_{b}^{f}, i_{c}^{f}, i_{d}^{f}, i_{e}^{f}\right)$ resulting in the following quantities:

$$
\left[i_{n}^{f}\right]=\left[i_{n}\right]+\left[f_{n}\right]
$$

where $\left[i_{n}^{f}\right]$ denotes the phase currents under fault conditions. $\left[i_{n}\right]=\left[\begin{array}{lllll}i_{a} & i_{b} & i_{c} & i_{d} & i_{e}\end{array}\right]$ are the phase currents in normal 
operation case and $\left[f_{n}\right]=\left[\begin{array}{lllll}f_{a} & f_{b} & f_{c} & f_{d} & f_{e}\end{array}\right]$ are the fault quantities corresponding to each phase of the PMSM.

Taking as an example an open circuit fault in T1 (upper switch of the phase $a$ in Fig. 1), is shown in Fig. 2. Indeed, the current in the phase $a$ is limited to flow only in the negative direction. By the additive representation defined in (7), $f_{a}$ will present a negative direction for this fault scenario. For example in simple case of sinusoidal phase current, the expression of $f_{a}$ is:

$$
f_{a}=\left\{\begin{array}{lc}
-I^{h 1} \sin (p \Omega t) \leq 0, & 0<p \Omega t<\pi \\
0, & \pi<p \Omega t<2 \pi
\end{array}\right.
$$

Contrariwise, now if the fault occurs in the lower switch of the phase a (T6 in Fig.1), the inverter can no longer synthesize the negative portion of the phase current, and $f_{a}$ will present only a positive direction but during the second half period. Table I shows the sign of the fault profiles $\left(f_{a}, f_{b}, f_{c}, f_{d}, f_{e}\right)$ according to the faulty switch location. However, as there exist ten power switches $\left(T_{1}, \ldots, T_{10}\right)$, ten fault directions can be defined. These quantities represent the key point for FDI process development. Mathematical development will be given in the next section.

Applying now the linear Concordia transformation in (4) and taking into account the additive representation done in (7), the faulty phase currents are expressed in Concordia frames by:

$$
\left[i_{\alpha \beta}^{f}\right]_{\text {Concordia }}=\sqrt{\frac{2}{5}}[C]^{T}\left[i_{n}^{f}\right]
$$

The resulting components in the decoupled subspaces $\alpha_{l} \beta_{l}$ and $\alpha_{3} \beta_{3}$ are expressed as follows:

$$
\left[\begin{array}{c}
i_{\alpha \beta 1}^{f} \\
i_{\alpha \beta 3}^{f}
\end{array}\right]=\left[\begin{array}{c}
i_{\alpha \beta 1} \\
i_{\alpha \beta 3}
\end{array}\right]+\left[\begin{array}{l}
f_{\alpha \beta 1} \\
f_{\alpha \beta 3}
\end{array}\right]
$$

with

$$
\begin{aligned}
& f_{\alpha 1}=\sqrt{\frac{2}{5}}\left(f_{a}+\cos \left(\frac{2 \pi}{5}\right) f_{b}+\cos \left(\frac{4 \pi}{5}\right) f_{C}+\cos \left(\frac{6 \pi}{5}\right) f_{d}+\cos \left(\frac{8 \pi}{5}\right) f_{e}\right) \\
& f_{\beta 1}=\sqrt{\frac{2}{5}}\left(\sin \left(\frac{2 \pi}{5}\right) f_{b}+\sin \left(\frac{4 \pi}{5}\right) f_{C}+\sin \left(\frac{6 \pi}{5}\right) f_{d}+\sin \left(\frac{8 \pi}{5}\right) f_{e}\right) \\
& f_{\alpha 3}=\sqrt{\frac{2}{5}}\left(f_{a}+\cos \left(\frac{4 \pi}{5}\right) f_{b}+\cos \left(\frac{8 \pi}{5}\right) f_{c}+\cos \left(\frac{12 \pi}{5}\right) f_{d}+\cos \left(\frac{16 \pi}{5}\right) f_{e}\right) \\
& f_{\beta 3}=\sqrt{\frac{2}{5}}\left(\sin \left(\frac{4 \pi}{5}\right) f_{b}+\sin \left(\frac{8 \pi}{5}\right) f_{c}+\sin \left(\frac{12 \pi}{5}\right) f_{d}+\sin \left(\frac{16 \pi}{5}\right) f_{e}\right)
\end{aligned}
$$

It can be seen, in equations (11) and (12), that the fault profiles in the original abcde-frame are reflected in the decoupled subspaces $\alpha_{1} \beta_{1}$ and $\alpha_{3} \beta_{3}$. This property is interesting when the resulting quantities can carry information about the faulty switches.

In order to facilitate the discussion of the fault contribution in the Concordia frames, the simulated results for a healthy inverter and under an open-circuit fault in $\mathrm{T} 1$ are depicted in

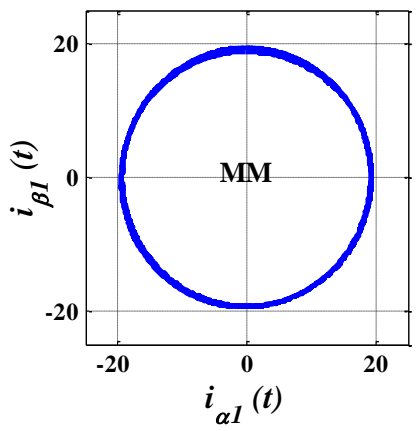

(a)

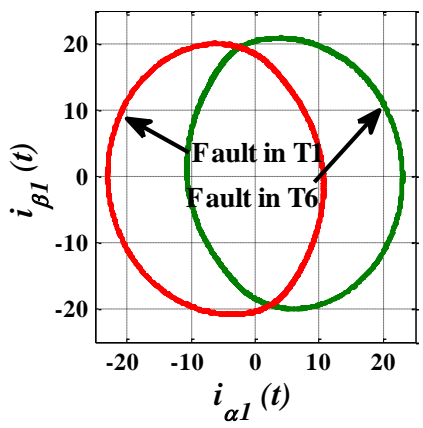

(c)

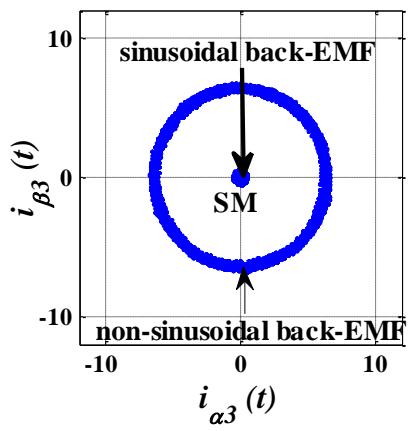

(b)

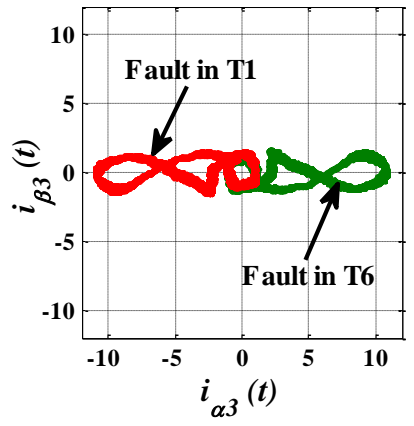

(d)
Fig. 3. Fault profile in Concordia frame.(a)-(b) healthy inverter. (c)(d) Open-circuit fault in T1(red) or T2 (green).(Small third harmonic).

Fig. 3 (a)-(d). Under normal conditions with phase currents containing only first and third harmonic components, the shapes are two circles centered at the origin for the two subspaces. Here, it is important to point out that for multiphase machines without third harmonic component (sinusoidal back-EMFs), the torque is only produced by the MM when a classical Maximum Torque Per Ampere Strategy (MTPA) of control is used. The shape of the $i_{\alpha 3}$ vs. $i_{\beta 3}$ is a point at the origin of the subspace $\alpha_{3} \beta_{3}$.

In a faulty case, regarding the Concordia reference frame $\alpha_{1} \beta_{1}$, it is clear that the shape taken by the current is similar to the healthy condition of the inverter but with a small deformation and displacement of the center of the shape. Contrariwise, in the Concordia reference frame $\alpha_{3} \beta_{3}$, the shape shows a typical trajectory. Its relative position and form characterize the faulty switch and can be used as input variable for the fault diagnostic process (FDP). Moreover, for a simple control, generally the torque is produced only by exciting the main machine through the $\mathrm{q}_{1}$-axis current only and the $\mathrm{d}_{1}$-axis, $\mathrm{d}_{3}$-axis and $\mathrm{q}_{3}$-axis current components are imposed to zero [9], [18]. As a consequence, there is no path for the third-harmonic of the current in healthy conditions of the electric drive system. This analysis has motivated the development of the FDI process based on the operating characteristic of the PWM-VSI PMSM in the decoupled subspace $\alpha_{3} \beta_{3}$-frame instead of using $\alpha_{1} \beta_{1}$-frame. The general steps required to find the FDI are then detailed.

\section{FAUlt DiAgnostic PROCESS}

The proposed FDI process is illustrated in Fig. 4. It consists in normalizing the input variables used by the algorithm, detecting and locating the open switch and open phase faults by using only the measured five phase currents. 


\section{A. Phase currents normalization}

Using the load currents without any conditioning could lead to false alarms during load transients. A way to overcome this problem consists in normalizing the phase currents given in (1) and (2). This task is achieved by using the modulus of the Concordia vector components. It is computed by the sum of the current modulus in each decoupled subspace as follow:

$$
\begin{aligned}
\left\|\vec{i}_{s}\right\| & \leq\left\|\vec{i}_{\alpha \beta 1}\right\|+\left\|\vec{i}_{\alpha \beta 3}\right\|=\sqrt{i_{\alpha 1}^{2}+i_{\beta 1}^{2}}+\sqrt{i_{\alpha 3}^{2}+i_{\beta 3}^{2}} \\
& \leq \sqrt{\frac{5}{2}}\left(I^{h 1}+I^{h 3}\right)
\end{aligned}
$$

For copper-losses optimization purposes in PMSM, the current vectors are generally collinear with the EMFs vectors (MTPA strategy). As a result, the ratio of the third current harmonic and the first one is the same as the ratio of the third back-EMF harmonic and the first one. However, it is quite easy to express the third harmonic component $I^{h 3}$ as a fractional ratio of the first harmonic as follows:

$$
I^{h 3}=\rho \cdot I^{h 1}
$$

Hence, the maximum current modulus (13) can be simply reduced to:

$$
\left\|\vec{i}_{s}\right\|_{\max }=\sqrt{\frac{5}{2}} I^{h l}(I+\rho)=\sqrt{\frac{5}{2}} I^{h 3}\left(1+\frac{l}{\rho}\right)
$$

It is clear that the maximum current modulus of $\vec{i}_{s}$ is a constant and depends only of the peak value of the first harmonic or the third harmonic, and the ratio $\rho$. These parameters can be easily experimentally fixed by measuring the back-EMFs of the PMSM [9].

Finally, the normalized quantities are obtained by dividing the phase currents by the maximum modulus as follows:

$$
i_{n_{-} N}(t)=\frac{i_{n}(t)}{\left\|\vec{i}_{\alpha \beta 1}\right\|+\left\|\vec{i}_{\alpha \beta 3}\right\|}
$$

$i_{n_{-} N}(t)=\sqrt{\frac{2}{5}}\left(\frac{1}{1+\rho}\right)\left(\sin \left[p \Omega t-(n-1) \frac{2 \pi}{5}\right]+\rho \sin \left[3\left(p \Omega t-(n-1) \frac{2 \pi}{5}\right)\right]\right)$

One of the important features is to work with normalized input variables of the diagnostic process, allowing the FDI strategy to be independent of the transient states. Such objective is justified when using equation (16) since there is no dependence of the current amplitude. For the five-phase PMSM under study the ratio $\rho \in\left[0 ; \frac{1}{9}\right]$. Consequently, the normalized quantities are within the range of $\pm \sqrt{\frac{2}{5}}((1-\rho) /(1+\rho))$.

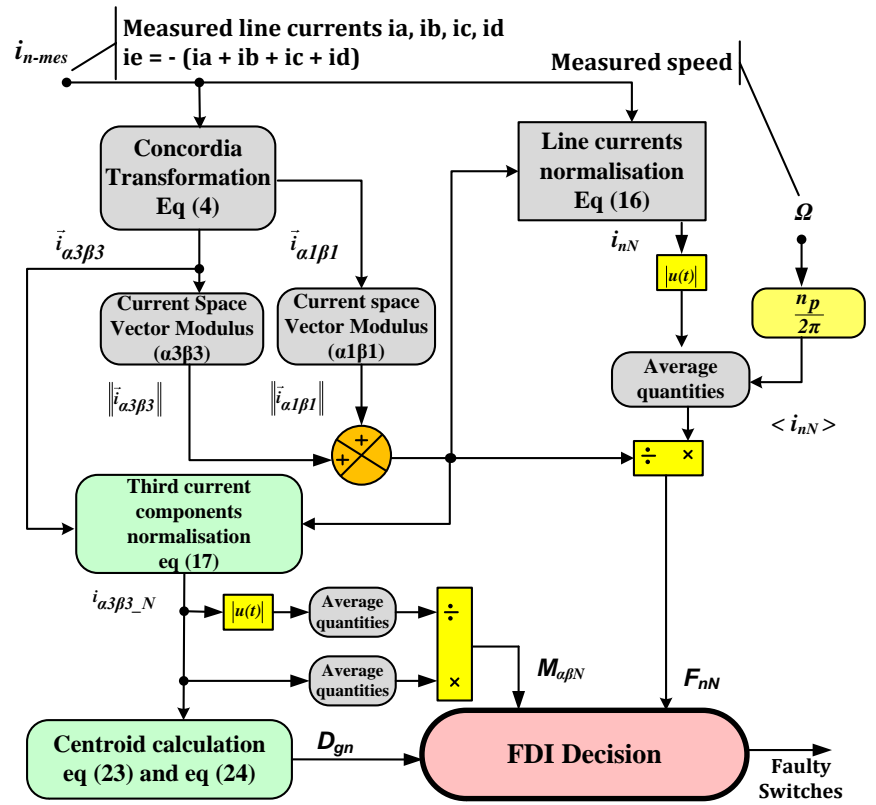

Fig. 4. Block diagram of the proposed FDI scheme

The current components in $\alpha_{3} \beta_{3}$-frame can be normalized in the same way as the phase currents, as follows:

$$
i_{\alpha \beta 3_{-} N^{(t)}}=\frac{i_{\alpha 3, \beta 3}}{\left\|\vec{i}_{\alpha \beta 1}\right\|+\left\|\vec{i}_{\alpha \beta 3}\right\|}=\left\{\begin{array}{l}
k_{\rho} \sin (3 p \Omega t) \\
k_{\rho} \sin \left(3\left(p \Omega t+\frac{\pi}{2}\right)\right)
\end{array}\right.
$$

with, $k_{\rho}=\frac{\rho}{1+\rho}$ is a constant value directly linked to the backEMFs's shape of the five-phase PMSM.

Once more, both Concordia vector components are completely independent from load operation conditions. The normalized quantities are within the range of $\pm k_{\rho}$.

\section{B. Reference Directions Definition in $\alpha 3 \beta 3$ Frame}

The second step in the FDI procedure consists in defining the reference directions of the fault profiles $\left(f_{a}, f_{b}, f_{c}, f_{d}, f_{e}\right)$ in $\alpha_{3} \beta_{3}$-frame. This step is mandatory since the fault appears in the original abcde-frame, thus permitting the knowledge of their equivalence in $\alpha_{3} \beta_{3}$-frame. This task is achieved by a direct evaluation of the faulty current components $\left(i_{\alpha \beta 3}^{f}=i_{\alpha \beta 3}+f_{\alpha \beta 3}\right)$, where $f_{\alpha \beta 3}$ denotes the reflected fault profiles done in (12). However, the evaluation of these current components under fault conditions is performed using their average values over a fundamental current period as:

$$
\left\langle i_{\alpha \beta 3}^{f}\right\rangle(t)=\frac{1}{T(t)} \int_{t-T(t)}^{T(t)}\left(i_{\alpha \beta 3}+f_{\alpha \beta 3}\right) d t
$$

Here, it should be noted that, regardless of the shape of the back-EMF and independently of the operation conditions of the system, the average values of the current $i_{\alpha \beta 3}$, corresponding to the healthy condition, are equal to zero 
theoretically. So, the expression given in (18) can be rewritten as follows:

$$
\left\langle i_{\alpha \beta 3}^{f}\right\rangle(t)=\left\{\begin{array}{l}
A_{v \alpha 3}=\frac{1}{T(t)} \int_{t-T(t)}^{T(t)} f_{\alpha 3} d t \\
A_{v \beta 3}=\frac{1}{T(t)} \int_{t-T(t)}^{T(t)} f_{\beta 3} d t
\end{array}\right.
$$

Where $A_{v \alpha 3}$ and $A_{v \beta 3}$ denote the average values of the faulty current components along $\alpha 3$-axis and $\beta 3$-axis, respectively.

By introducing (12) in (19), the reference directions are expressed as follows:

$$
d_{n-r e f}=a \tan \left(\frac{A_{v \alpha 3}}{A_{v \beta 3}}\right)=\left\{\begin{array}{lll}
\pi-(k-1) \frac{2 \pi}{5}, & \text { if } & f_{n}(t) \leq 0 \\
-(k-1) \frac{2 \pi}{5}, & \text { if } & f_{n}(t) \geq 0
\end{array}\right.
$$

where

- $n$ represents the phases $a, b, c, d, e$,

- $k=1,4,2,5,3$ are respectively associated to the phases $a, b, c, d, e$ when the fault occurs.

Fig. 5 shows all reference directions according to the faulty switch. The same results are given in Table II with the corresponding average values of the current components in Concordia frame. For illustration, let us take an example of the open-circuit fault of the T6 transistor (lower switch in leg a). In this case, the current in the phase a cannot flow in the positive direction, resulting in a positive fault profile $f_{a}(t)$. In $\alpha_{3} \beta_{3}$-frame, this fault shows a typical shape which can be characterized with its reference direction which has been computed based on the average values of the Concordia currents given by:

$$
\left\langle i_{\alpha \beta 3}^{f}\right\rangle(t)=\left\{\begin{array}{l}
A_{v \alpha 3}=\sqrt{\frac{2}{5}} \frac{I m}{\pi} \\
A_{v \beta 3}=0
\end{array}\right.
$$

Then, using (21), the resulting reference direction for this fault scenario becomes equal to $\left(d_{n-r e f}=0^{\circ}\right)$. All the previous explanations can be extended to the remaining phases $(b, c, d$ and $e$ ) including upper and lower power switches.

\section{Centroid-based FDI method}

As discussed in the above section, the fault detection process is based on the knowledge of the output line current patterns in Concordia subspace $\alpha_{3} \beta_{3}$. An analytical model to describe the modulation of these patterns in such a frame can be achieved by using the centroid method based on the vector space representation. It denotes the central value of a set of data over one fundamental period of the current. There are several algorithms to compute the centroid. In this paper, a very simple geometric method is chosen for this application, as shown in Fig.6. For the system under study, there are ten

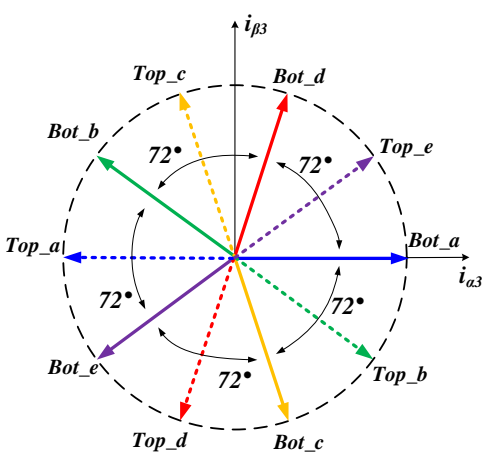

Fig. 5. Reference directions in a3ß3-frame.

TABLE II

REFERENCE DIRECTIONS EVALUATION IN FAULTY CASE

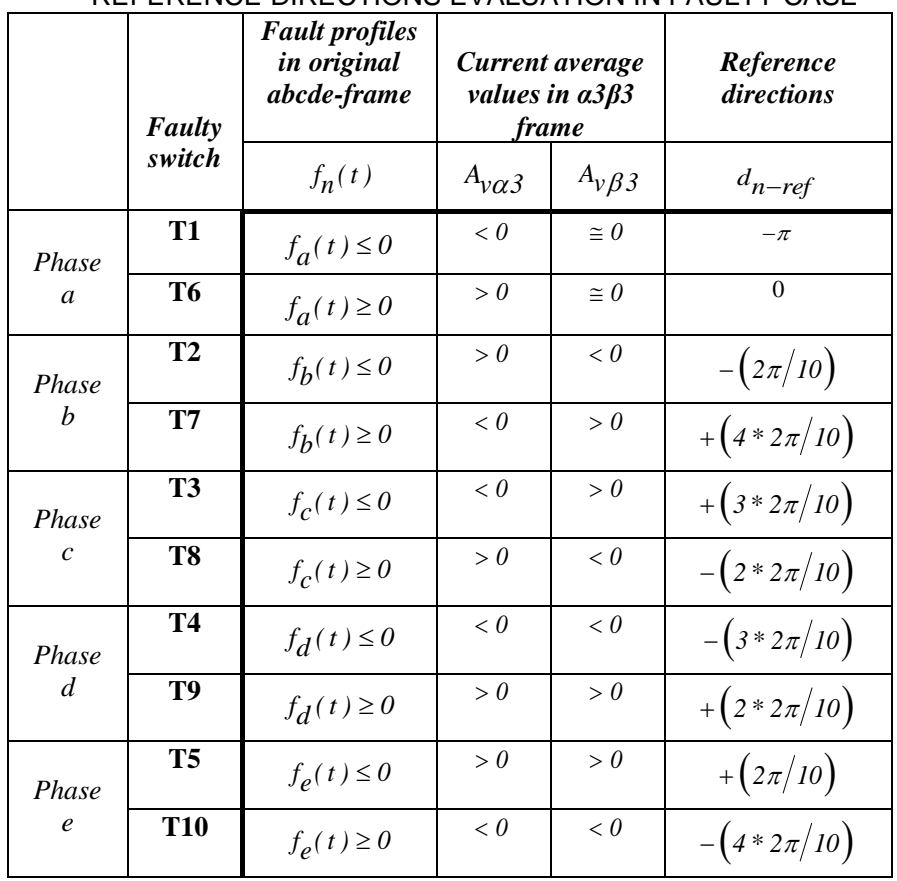

typical shapes built with the output inverter currents in $\alpha_{3} \beta_{3}$ frame, which are used to detect the faulty operation modes. Five of them are linked to the open-circuit faults in the upper MOSFETs of the VSI and the others to the open-fault modes of the lower MOSFETs switches. Each typical shape is represented by a reference direction and sign (as shown in Table II and Fig.5). The equation to calculate the centroid vector for each sampling period, shown in Fig. 6, is given by:

$$
\vec{G}_{i_{-} \operatorname{samp}}=\frac{1}{3}\left(\overrightarrow{O O}+\overrightarrow{O M}+\overrightarrow{O P_{i}}\right)
$$

where, $\quad \vec{G}_{i_{-} \text {samp }}=\overrightarrow{O G}_{i}$ denotes the instantaneous centroid vector of the triangle formed by the fixed points $O(0,0)$, $M\left(M_{i \alpha 3-N}, 0\right)$ and the variable point $P_{i}\left(P_{i \alpha 3-N}, P_{i \beta 3-N}\right)$. The measured currents are sampled $N_{p}$ times per fundamental cycle with centroid positions $G_{l}, G_{2}, \ldots, G_{N p}$. The global centroid vector over a fundamental current period is given by: 


$$
\vec{G}_{g}=\frac{1}{N_{p}} \sum_{i=1}^{N_{p}} \vec{G}_{i_{-}} \operatorname{samp}
$$

The vector $\vec{G}_{g}=\overrightarrow{O G}_{g}$ is with the one of the reference directions defined in Table II, thus characterizing the typical shapes corresponding to the faulty cases.

Here, it should be noted that the position of $\vec{G} g$ is equal to zero theoretically under normal conditions. However, the fault in the upper switch of the inverter first leg $\left(\mathrm{T}_{1}\right.$ in phase $\left.a\right)$ is indistinguishable from the healthy case. To prevent this misinterpretation and for more effectiveness of the proposed method, the sign of each normalized average current component $\left(i_{\alpha 3_{-} N}, i_{\beta 3_{-} N}\right)$ is used. These quantities with those derived from (11) can detect and localize the faulty switch in the VSI. They are expressed using the following relationship:

$$
\left\{\begin{array}{l}
D_{g n}(t)=\arg \left(\frac{1}{N_{p}} \sum_{i=1}^{N_{p}} \vec{G}_{i_{-} \operatorname{samp}}\right)=\operatorname{atan}\left(\frac{G_{g \beta 3}}{G_{g \alpha 3}}\right) \\
M_{\alpha \beta 3 N^{(}}(t)=\frac{\left\langle i_{\alpha \beta 3 \_N}\right\rangle(t)}{\left\langle\left|i_{\alpha \beta 3} N\right|\right\rangle(t)}
\end{array}\right.
$$

where $G_{g \alpha 3}$ and $G_{g \beta 3}$ are the $\alpha_{3}$-axis and the $\beta_{3}$-axis coordinates of the global centroid over fundamental current period. $M_{\alpha \beta 3 N}$ denotes the average values of the normalized current components in $\alpha_{3} \beta_{3}$-frame defined in (17).

Regarding the variable $D_{g n}$, it is equal to zero theoretically under normal operating conditions. Contrariwise, in the case of an open-circuit fault, the $D_{g n}$ variable will assume a distinct positive or negative value. This value corresponds to the direction of centroid in $\alpha_{3} \beta_{3}$-frame and characterizes the position of the typical shapes presented in section II, indicating the open-circuit fault occurrence in the VSI.

Regarding the $M_{\alpha \beta 3 N}$ variables, they are equal to zero theoretically under normal operation mode because the Concordia current components in $\alpha_{3} \beta_{3}$-frame are equal to zero or present a symmetrical sinusoidal waveform according to the strategy used for the closed control of the PMSM. Under faulty operation modes, these variables are in the range $\pm[0.77,1]$ for the system under study with the ratio $\rho \in$ $[0,0.11]$, as explained in Table II. This information and the one derived from the variable $D_{g n}$ allow an accurate detection and localization of the faulty switch.

The diagnostic variables defined in (24) carry information about only the single open-switch fault. In order to complete the diagnosis and extend the FDI process for open phase fault (two switches of the same legs are opened), the normalized quantities derived from the phase currents are used as follows:

$$
F_{n_{-} N}(t)=\frac{\left\langle\mid i_{n N} \|\right\rangle(t)}{\left\|\vec{i}_{\alpha \beta_{-}}\right\|+\left\|\vec{i}_{\alpha \beta_{-} 3}\right\|}
$$

Regarding the $F_{n_{-} N}$ variables, they are nonzero for a healthy electric drive system since the current modulus in Concordia frame as well as the average absolute value of the

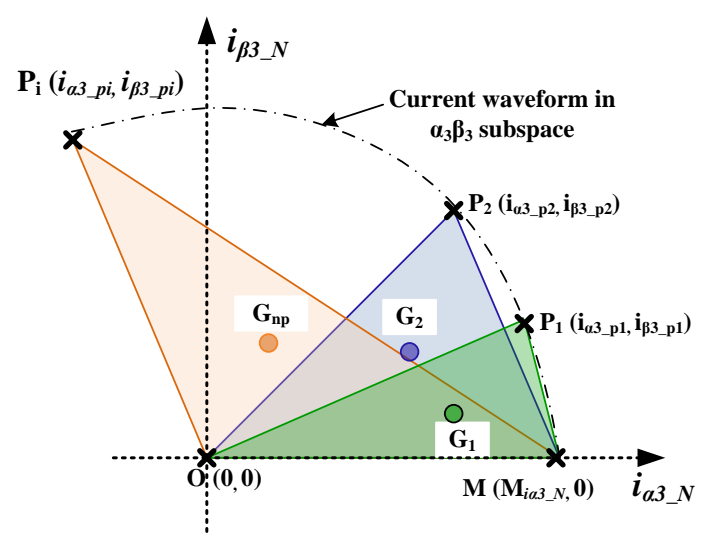

Fig. 6. Centroid-based fault Method principle

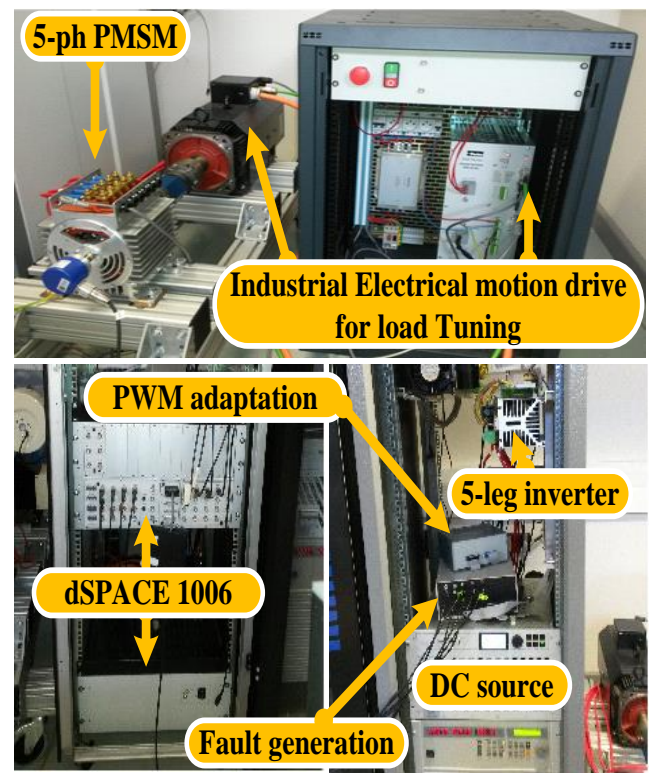

Fig. 7. Overview of the experimental test bench

TABLE. III

FIVE PHASE PMSM PARAMETERS

\begin{tabular}{|c|c|c|c|c|c|c|c|}
\hline $\mathrm{R}(\mathrm{m} \Omega)$ & $\begin{array}{c}\mathrm{L}_{\mathrm{p}} \\
(\mathrm{mH})\end{array}$ & $\begin{array}{c}\mathrm{L}_{\mathrm{s}} \\
(\mathrm{mH})\end{array}$ & $\mathrm{p}$ & $\begin{array}{c}\text { Ipeaksinus } \\
(\mathrm{A})\end{array}$ & $\begin{array}{c}\text { DC-bus } \\
\text { Voltage }(\mathrm{V})\end{array}$ & $\begin{array}{c}\text { Base } \\
\text { Speed } \\
(\mathrm{rpm})\end{array}$ & $\begin{array}{c}\text { Maximum } \\
\text { Torque } \\
(\mathrm{N} . \mathrm{m})\end{array}$ \\
\hline 9.1 & 0.12 & 0.05 & 7 & 180 & 48 & 1700 & 50 \\
\hline
\end{tabular}

motor currents $\left\langle\left|i_{n N}(t)\right|\right\rangle$ are both positive. In the case of an open phase fault, the average absolute value of the current in faulty phase becomes null, resulting in a null values of the $F_{n_{-} N}$ variables corresponding to a faulty inverter leg.

\section{EXPERIMENTAL EVALUATION OF THE PROPOSED FDI}

\section{A. Test Bench Description}

The evaluation of the proposed approach is performed by using a low-voltage $10 \mathrm{~kW}$ peak five-phase PMSM coupled to an industrial motion drive that is used to speed and load profile changes. A photograph of the test bench is shown in Fig. 7. The proposed diagnosis scheme is tested in a closed loop vector control. The control and the FDI algorithms are implemented by using a dSPACE 1006 controller board, running at a sampling frequency of $25 \mathrm{kHz}$. The five-phase inverter is constructed by using SEMIKRON MOSFET 
components (SK260MB10). The switching signals for all MOSFETs are generated from the dSPACE DS1006 board through an adaptation stage from $5 \mathrm{~V}$ to $15 \mathrm{~V}$. The PWM-VSI is running with $15 \mathrm{kHz}$ as switching frequency. To create the open switch or open phase fault, the gate signals of the faulty transistors are forced to zero by using fast analog circuits that are also controlled through the dSPACE DS1006.

\section{B. Experimental Results}

\section{1) FDI Implementation and thresholds selection}

A signal processing is performed before applying the FDI algorithm. It consists in sampling and filtering the phase currents. However, a second order filter is designed to attenuate the high switching frequency as well as the measure noise induced by the current and speed sensors. Cut-off frequency of the filter is set to $1 \mathrm{kHz}$ with a damping factor fixed to $\zeta=0.707$. The time delay is about $2 \%$ of the fundamental current period when considering the maximum rotor speed which up to $178 \mathrm{rd} / \mathrm{s}$ (1700 rpm) for the five-phase PMSM under study. Consequently, there is no effect on the performance of the proposed FDI algorithm.

Regarding the thresholds, there are three threshold values used by the proposed algorithm. Generally, the robustness and the resistivity of the FDI process against false alarms are very dependent of the threshold values used for fault diagnosis. But in this work, a faulty model based on the normalized variables derived all from the output inverter currents is given in section III. Based on this model, the threshold values can be calculated by integration of the analytical expressions. All used thresholds are defined as follows:

- $\quad D_{T h}$ is used to decide on the position of the $D_{g n}$ variable. This variable is considered as a characteristic value of the average centroid value characterizing the output inverter currents trajectory in $\alpha \beta 3$-frame. In fact, the fault occurrence in the VSI results in alignment of the centroid vector with one of the reference directions defined in section III (eq.20). But, because the multiple high order harmonics induced by the PWM-Switching process and sensor noise, the $D_{g n}$ variable will not be exactly with their relative reference directions. Consequently, the $D_{g n}$ variable will be within the interval $\left[d_{n-r e f} \pm D_{T h}\right]$. For the system under study, $D_{T h}$ is set to $10^{\circ}$. The selected threshold guarantees a large dissymmetry between each two successive reference directions which is equal to $16^{\circ}$.

- The second threshold $M_{T h}$ is used to decide on the sign of the current components in $\alpha \beta_{3}$-frame. These variables together with the $D_{g n}$ variable allow a more robust faulty switch detection and localization. Under healthy conditions, the $M_{\alpha \beta 3 N}$ variables are equal to zero theoretically. On the contrary, they will be either positive within the range $[0.77,1]$ or negative within $[-0.77,-1]$ according to the ratio $\rho(\rho \in[0,0.11]$ for the PMSM under study) and according to the involved faulty switch. So, these variables are considered positive if $M_{\alpha \beta 3 N}$ is greater than $M_{T h}$ and negative if $M_{\alpha \beta 3 N}$ is less than $M_{T h}$. In this work, the threshold $M_{T h}$ (a) Healthy VSI

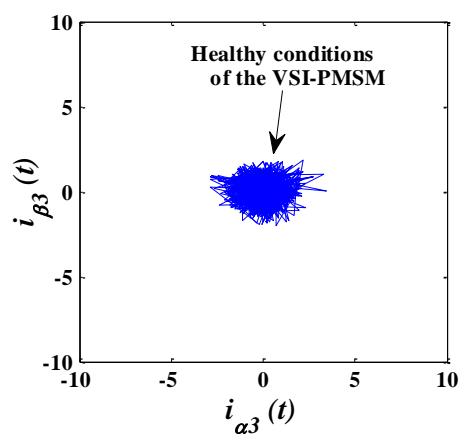

(c) A step transition from $25 \%$ to $75 \%$ of the rated load.

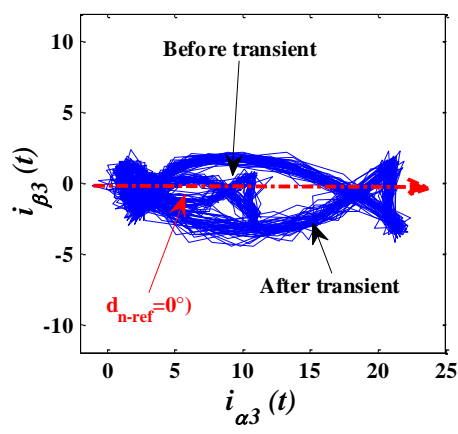

(b) A step transition from $10 \%$ to $75 \%$ of the rated load.

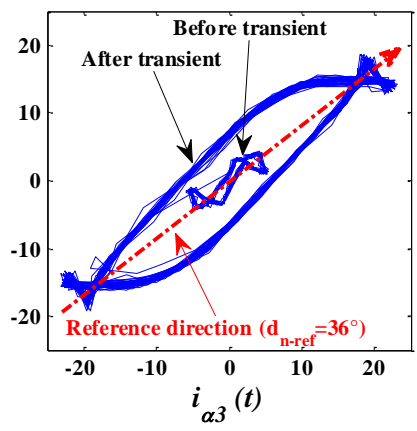

(d) A step transition from 200 rpm to $600 \mathrm{rpm}$ and $75 \%$ of the rated load.

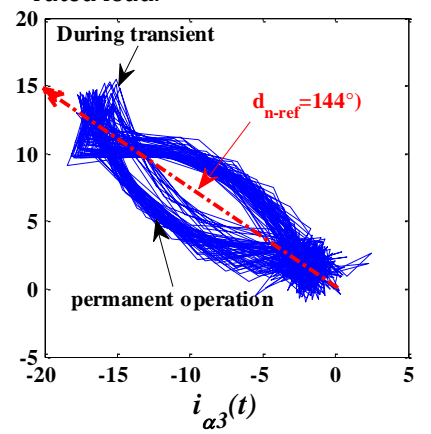

Fig. 8. Measured typical shapes for a healthy and faulty conditions. (a)healthy VSI. (b) open phase fault. (c) an upper open switch fault (T7). (d) a lower open switch fault (T6)

the occurrence of the fault, the phase current $\mathrm{i}_{\mathrm{b}}$ suddenly reaches zero and is limited now to flow only in the positive conditions such as speed and load changes, and fault modes.

- The third threshold $F_{T H}$ is used to decide on the openphase fault occurrence in the VSI. In fact under healthy conditions, this variable is always nonzero within the range $[0.35,0.4]$. On the contrary, this variable drops to zero when an open phase fault occurs in the inverter. In this work, $F_{T H}$ it is chosen to be equal to +0.1 to guarantee a good detection speed and a good discrimination between transient conditions such as speed and load changes, and fault modes.

Here it should be noted that the selected thresholds have been also verified by simulation and by running experiments for both a healthy and a faulty operation conditions.

\section{2) PMSM Operating characteristics under VSI fault} conditions and FDI immunity to false alarms

The results presented in this subsection have two main goals. The first one is to show the experimental results of the typical shapes built by the output inverter currents in $\alpha_{3} \beta_{3^{-}}$ frame for healthy and faulty conditions. The second one is to study and verify the FDI immunity and robustness under severe conditions such as speed and load torque changes.

The experimental results, reported in Fig. 8, show the line currents trajectories in $\alpha_{3} \beta_{3}$-frame for a healthy VSI and under fault conditions, such as an open switch or an open phase fault. Regarding the normal operation mode (Fig. 8(a)), the shape built by the output inverter currents in $\alpha_{3} \beta_{3}$-plane 
corresponds to a point localized at the origin. Similar to the classical control strategies, the torque is produced only by exciting the main machine through the $\mathrm{q}_{1}$-axis current. However, there is no path for the third current harmonic under healthy conditions of the electric drive system. Thus, the observed low magnitude of the current is due only to the high switching frequency and noise measurement. In addition, it should be noted that if the third harmonic is also used to produce the torque in the closed loop control, the presented shape before will be a circle.

The measured shapes in $\alpha_{3} \beta_{3}$-frame under faulty conditions are reported in Fig. 8(b)-(d). In this evaluation, fast transient processes are imposed by a change of the reference speed or the load torque. In Fig. 8(b) and (c), the transient process is imposed by step increase of the load torque under simultaneous open circuit fault in two MOSFETs (T5 and T10) belonging to the same inverter leg (Fig. 8(b)), and single fault in transistor T6 (Fig.8(c)), respectively. For these two cases, the PMSM is running at $600 \mathrm{rpm}(70 \mathrm{~Hz})$. Here, the typical shape characterizing the fault condition, in leg $a$ and $\operatorname{leg} e$, remain unchanged and with the same reference direction $d_{n-\text { ref }}$ under varying operation conditions. Only the magnitude changes according to the load ratio, as reported on these figures.

Fig. 8(d) corresponds to the open-circuit fault of the lower transistor T6 in first inverter leg and a step increase of the reference speed from $200 \mathrm{rpm}$ to $600 \mathrm{rpm}$. Similar to the previous cases, the typical shape characterizing the fault is the same for all operating conditions. Here it should be noted that each shape built by the currents is characterized by its centroid position defined in (24). Regarding this characteristic value $D_{g n}$, it is clear that it always remains unchanged by the load or speed changes since the typical shapes have the same centroid before, during and after load or speed change. From these evaluation tests, it is clear that the fault detection can be achieved for all operating conditions without false alarms.

Another experimental test is addressed in Fig. 9 to verify the robustness and the immunity of the proposed FDI process under severe conditions. From top to bottom, the time-domain waveforms of the mechanical rotor speed, the phase currents, the diagnostic variable $D_{g n}$, the diagnostic variables $M_{\alpha \beta 3 N}$ and the diagnostic variables $F_{n_{-} N}$ are given, respectively. The fivephase PMSM accelerates from $30 \mathrm{rad} / \mathrm{s}$ to $100 \mathrm{rad} / \mathrm{s}$ simultaneously with a step transition of the load torque from $10 \%$ to $75 \%$ of its rated value. Regarding the diagnostic variables, it is observed that are always within the range corresponding to the healthy state of the VSI, resulting in no false alarms in the FDI process

Extensive tests have also been analyzed for several other conditions. The obtained results proved that the proposed FDI process is robust against the five-phase PMSM parameters variation (the back-EMF, the resistance and the inductance), the DC-bus voltage fluctuation and transistor aging effects resulting in a change of the drain-source resistance $\left(\mathrm{R}_{\mathrm{DS}-\mathrm{ON}}\right)$.

\section{1) FDI effectiveness and performances evaluation}

The experimental results reported in Fig. 10 and Fig. 11 address the diagnosis technique capabilities under low load conditions of the PMSM. In this evaluation, the load torque is
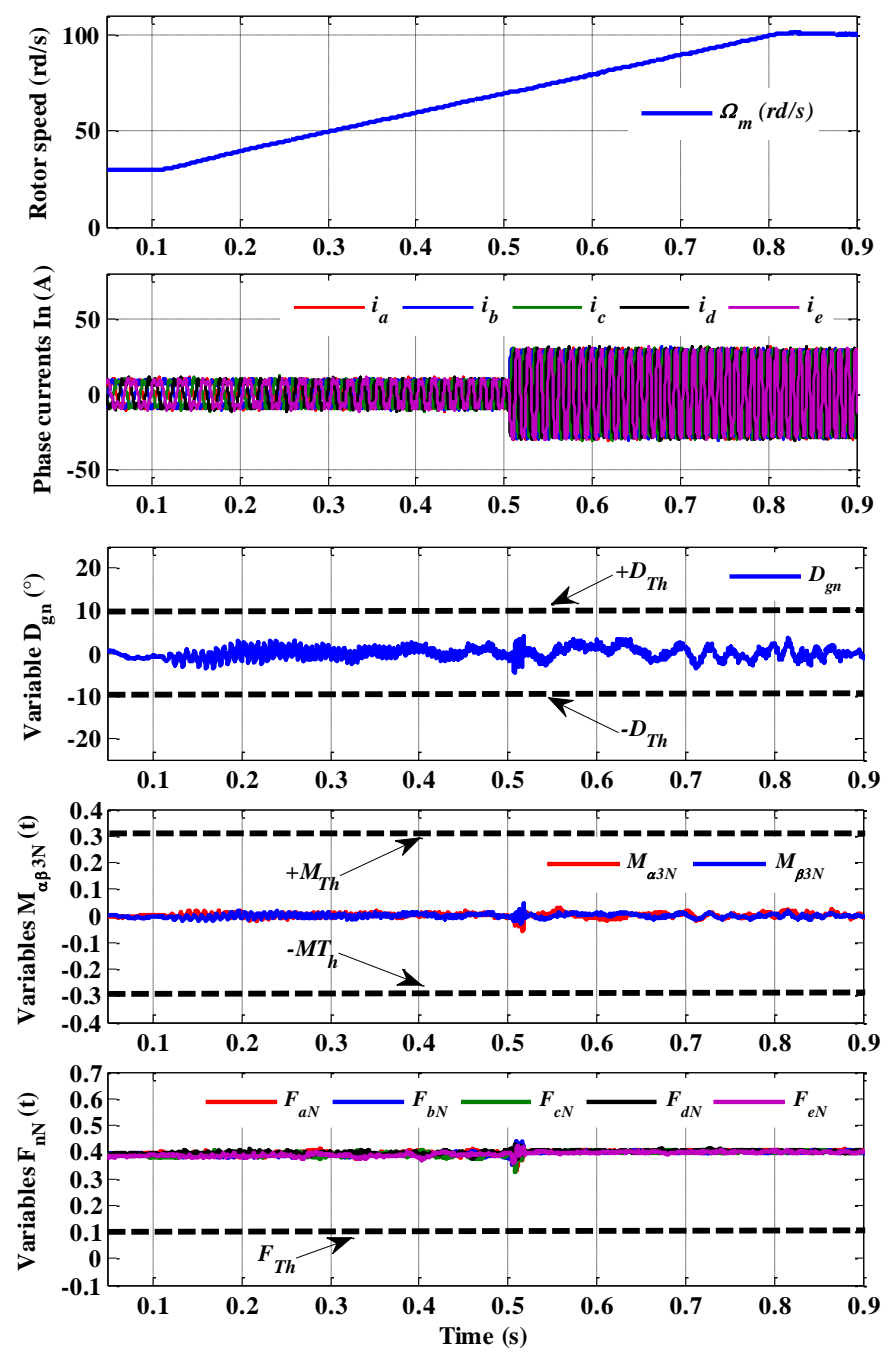

Fig. 9. Robustness of the proposed method under transient states. Experimental waveforms of the mechanical rotor speed, the phase currents, the variable $D_{g n}$, the variable $M_{\alpha \beta 3 N}$ and the variables $F_{n N}$ under healthy condition and a simultaneous change of the rotor speed and the load.

fixed to $10 \%$ of its rated value. The motor speed is fixed to $428 \mathrm{rpm}$ so that fundamental frequency of the phase current is equal to $50 \mathrm{~Hz}$.

Fig. 10 presents the experimental spectrogram of the PMSM phase $b$ current for a healthy inverter and for an open switch fault of MOSFET T7. Comparing the two spectrums under the two operating conditions, it is obvious that the multiples faulty frequency components indicate the maloperation of the whole electromechanical system.

Considering Fig. 11, it presents the time-domain waveforms of the line currents, the variable $D_{g n}$, the variables $M_{\alpha \beta 3 N}$ and the variables $F_{n_{-} N}$. Under low load operating conditions, the phase currents present a significant harmonic distortion. As a result, a small ripple is observed on the diagnosis variables but without impact on the robustness and the immunity of the FDI process. The open circuit fault is due to the lower T7 in the second inverter leg $b$ at $\mathrm{t}=0.263 \mathrm{~s}$, by keeping its switching signal permanently in "Off" state. After the occurrence of the fault, the phase current $i_{\mathrm{b}}$ suddenly reaches zero and is limited now to flow only in the positive 


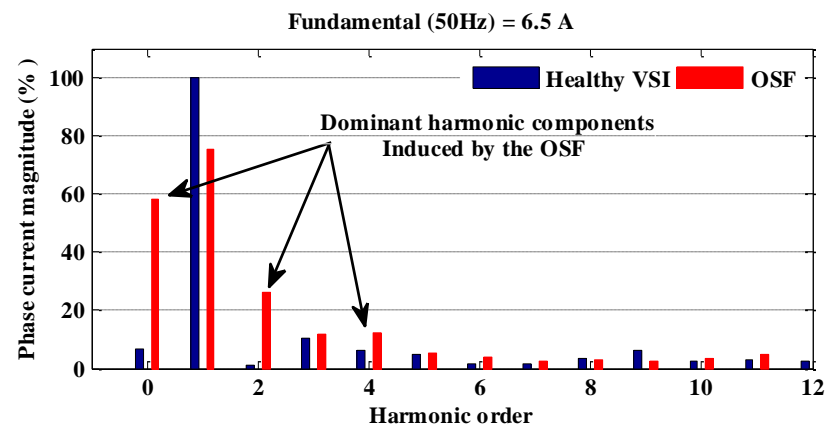

Fig. 10. Experimental results : spectrogram of the faulty phase current $i_{b}$ under healthy inverter and when an open-circuit fault of MOSFET (T7) occurs.
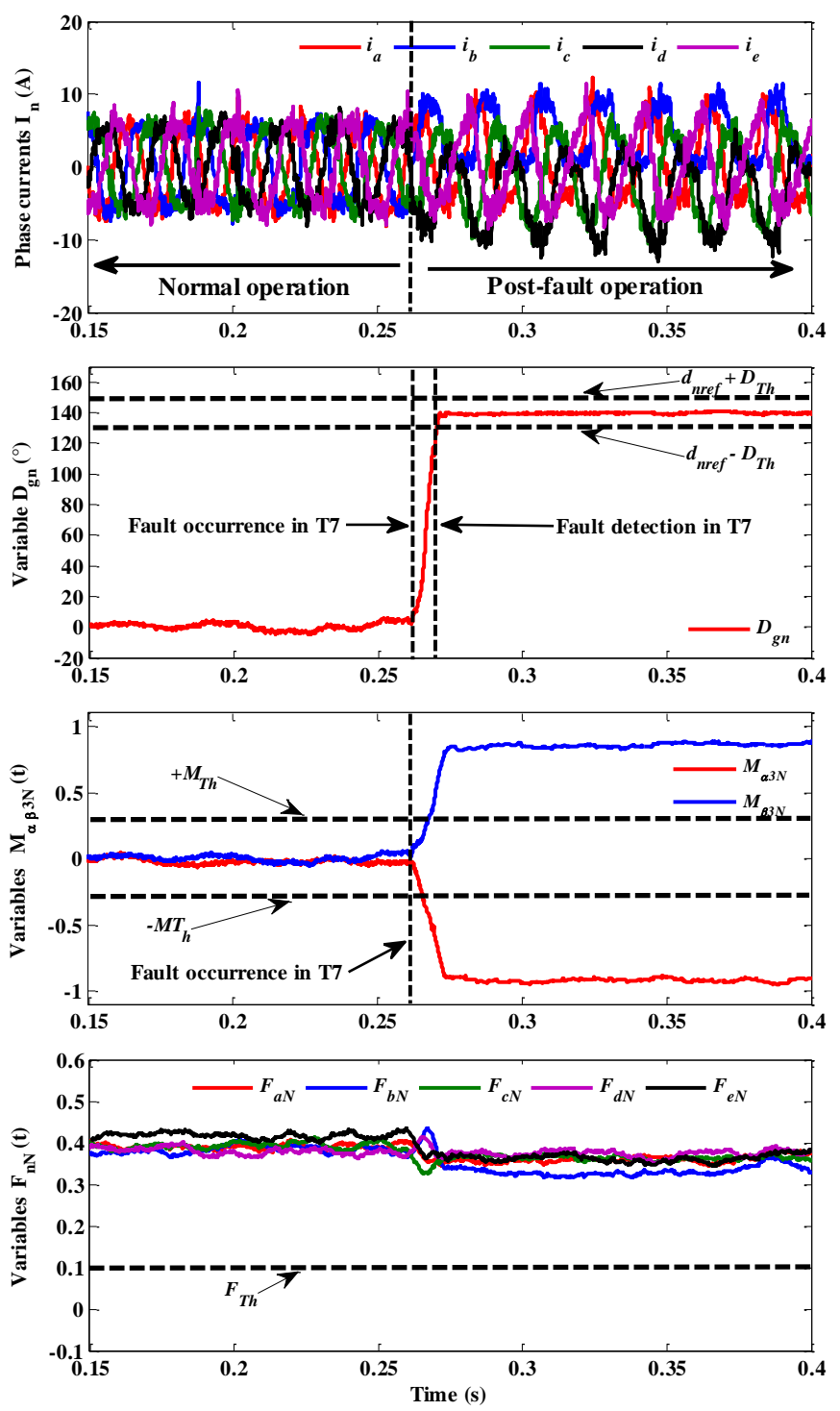

Fig. 11. Experimental waveforms of the phase currents, the variables $D_{g n}$, the variable $M_{\alpha \beta 3 N}$ and the variables $F_{n N}$ for an open-circuit fault of MOSFET (T7) in leg $b$.

direction, while other currents undergo a light deformation and are flowing in negative and positive directions. Regarding the variable $D_{g n}$, it is observed that it increases immediately and converges to the positive level near to $144^{\circ}$, corresponding to a fault profile of T7 in $\alpha_{3} \beta_{3}$-frame. The fault profile position in

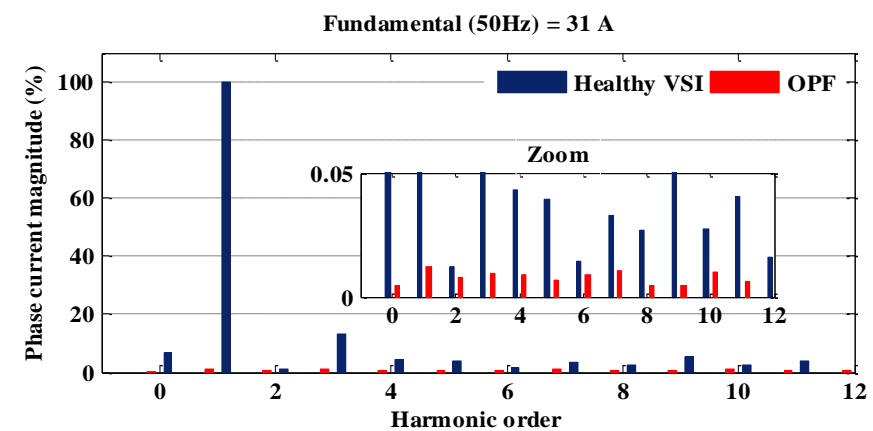

Fig. 12. Experimental results: spectrogram of the faulty phase current $i_{e}$ under healthy inverter and when an open-phase fault occurs in the $\operatorname{leg} e$.
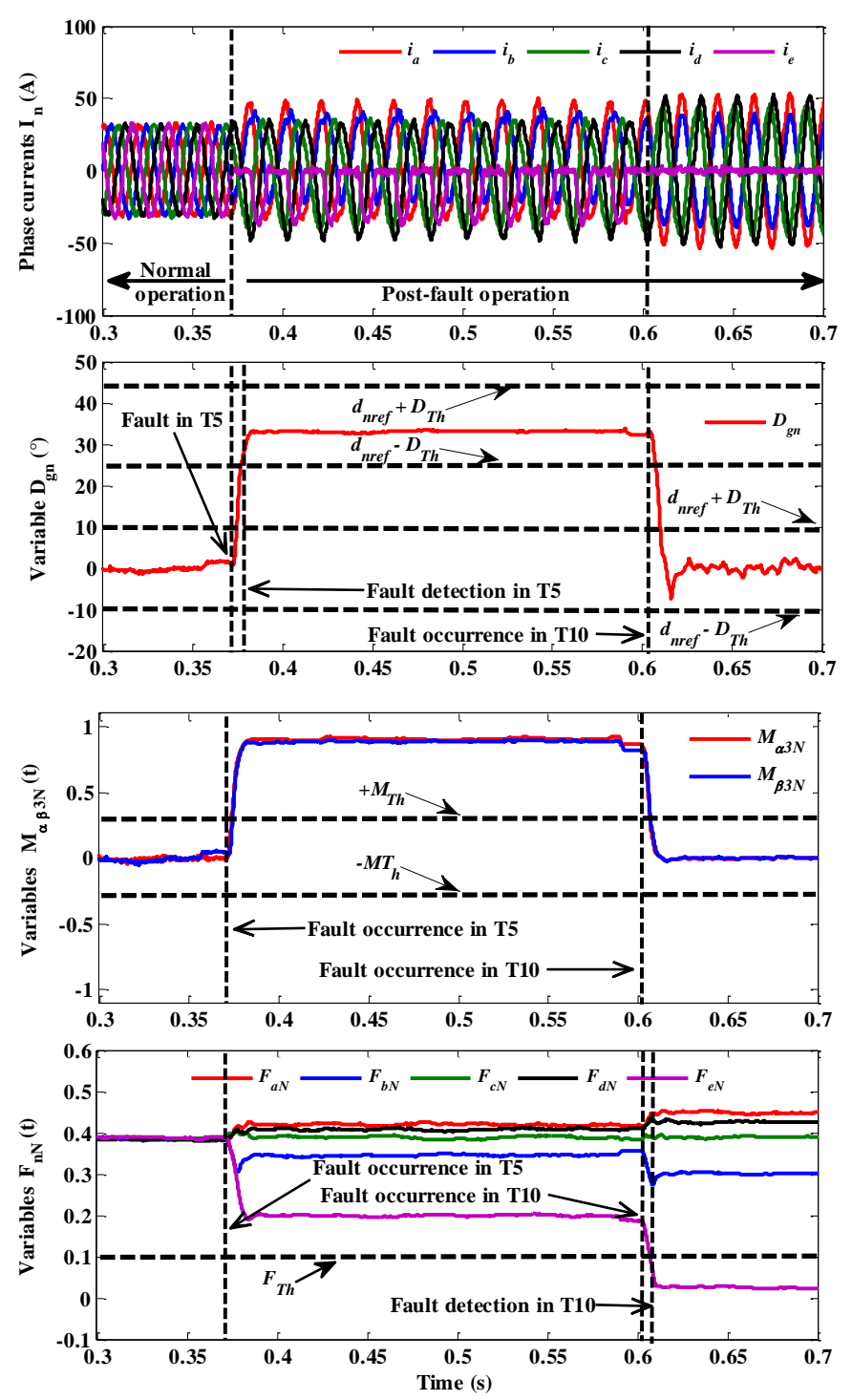

Fig. 13. Experimental waveforms of the phase currents, the variables $D_{g n}$, the variable $M_{\alpha \beta 3 N}$ and the variables $F_{n N}$ for an open-circuit fault of T5 and then an open phase of the leg e (T5 and T10)

$\alpha_{3} \beta_{3}$-frame are confirmed by the signs of the average current components $i_{\alpha 3}$ and $i_{\beta 3}$ through the variables $M_{\alpha 3 N}$ and $M_{\beta 3 N}$ which reach the fixed thresholds and become close to +1 and 1 , respectively, after the fault occurrence. However, fast detection in $\mathrm{T} 7$ is achieved at $\mathrm{t}=0.2678 \mathrm{~s}$, since it takes only 
$4.8 \mathrm{~ms}$ to detect the fault in the power switch (with a time delay near to $24 \%$ of the fundamental current period). Regarding the variables $F_{n N}$, they are always within the levels corresponding to no open-phase fault in the VSI.

Let us now consider a fault scenario involving, firstly, an open circuit of the upper switch of phase $e$ (T5), and then an open phase fault in the same inverter leg (T5 and T10).

Fig. 12 presents the experimental spectrogram of the phase $e$ current for a healthy inverter and an open phase fault of the leg $e$. By comparing the two spectrums, it is obvious that the very low magnitudes of the frequency components under fault condition indicate the loss of the leg $e$.

Regarding Fig. 13, it presents the experimental results regarding the output inverter currents, the variable $D_{g n}$, the variables $\mathrm{M}_{\alpha \beta 3 \mathrm{~N}}$ and the variables $F_{n_{-N}}$ used for fault diagnosis. For this test, $75 \%$ of the load torque is applied to the PMSM with a reference speed fixed to $428 \mathrm{rpm}$ (the fundamental frequency is equal to $50 \mathrm{~Hz}$ ). At $\mathrm{t}=0.372 \mathrm{~s}$, an open-circuit fault is introduced in transistor T5, by keeping gate signal S5 in "Off" state. After this instant, only the phase current $i_{e}$ is limited to flow in a negative direction. Regarding the variable $D_{g n}$, it reaches the level equal to $36^{\circ}$, corresponding to the centroid position of the fault profile in T5. Regarding the variables $M_{\alpha \beta 3 N}$, they converge immediately to +1 after the fault occurrence. Similar to the previous case, fast fault detection of the faulty switch T5 is achieved at t $=0.377 \mathrm{~s}$, since it takes only $5 \mathrm{~ms}$ as a time delay ( $25 \%$ of fundamental period). At $\mathrm{t}=0.603 \mathrm{~s}$, a second fault is imposed to the lower switch T10 in the same inverter leg (phase e). As a result, current $i_{e}$ becomes constantly null over the whole period. Regarding the $D_{g n}$ value and the $M_{\alpha \beta 3 N}$ values, they suddenly drop to zero and remain null over the whole fundamental current period without causing false alarms. Here, it should be noted that the values of these variables are not relevant for this situation since they correspond to the values of the healthy conditions. However, to prevent this misinterpretation and to improve the effectiveness of the proposed method, the information about the faulty phase is achieved based on the normalized $F_{n_{N} N}$ variables. Regarding these quantities, it is observed that $F_{e N}$ is equal to zero after the fault occurrence in T10 Once more, fast fault detection of the open phase is achieved after $6 \mathrm{~ms}$ (fault identification is achieved at $\mathrm{t}=0.607 \mathrm{~s}$, which is about $20 \%$ of the fundamental period).

\section{CONCLUSION}

A real time, fast and low cost new algorithm for openswitch fault diagnostic in PWM-VSI feeding five-phase PMSM was proposed in this paper. It needs only the measured output inverter currents that are already available for a closedloop control of the electric drive, avoiding thus the use of additional sensors, complex hardware or complex calculations. The most important goal is to achieve a reconfiguration for the continuity of electric drive operation, or to obtain a corrective action to avoid the propagation of the fault in the other parts of the whole system.

The new proposed approach is derived from the operating characteristics of the five-phase PMSM under faults conditions. It uses multiple normalized diagnosis variables based on the current patterns in the decoupled $\alpha_{3} \beta_{3}$ subspace and other variables derived also from the normalized phase currents. These normalized variables, as well as the reference directions, which are unchanged during the transient states, make the FDI process completely independent of operating conditions. The validity and the feasibility of the proposed method are experimentally verified.

\section{REFERENCES}

[1] Xiaoyan Huang, A. Goodman, C. Gerada, F. Youtong, L. Qinfen, "Design of a five-phase brushless DC motor for a safety critical aerospace application," IEEE Trans. Indus. Electron., vol. 59, no. 9, pp. 3532-3541, Sept. 2012.

[2] Method for manufacturing a multi-phase synchronous rotating electric machine, and corresponding machine," by B. Aslan, E. Semail, J. Legranger. (2014, 11, 19). EP2804299 (A2). Available: https://data.epo.org/publication-server.

[3] V. I. Patel, Jiabin Wang, Weiya Wang, Xiao Chen, "Six-phase fractional-slot-per-pole-per-phase permanent-magnet machines with low space harmonics for electric vehicle application," IEEE Trans. Indus. Electron., vol. 50, no. 4, pp. 2554-2563, July-Aug. 2014.

[4] F. Mekri, S. Ben Elghali, M.E.H. Benbouzid, "Fault-tolerant control performance comparison of three- and five-phase PMSG for marine current turbine applications," IEEE Trans. Sustain. Energy, vol. 4, no. 2, pp. 425-433, April 2013.

[5] E. Prieto-Araujo, A. Junyent-Ferre, D. Lavernia-Ferrer, O. GomisBellmunt, "Decentralized control of a nine-phase permanent magnet generator for offshore wind turbines," IEEE Trans. Energy Convers., vol. 30, no. 3, pp. 1103-1112, Sep. 2015.

[6] E. Levi, "Multiphase electric machines for variable-speed applications," IEEE Trans. Indus. Electron., vol. 55, no. 5, pp. 1893-1909, 2008.

[7] F. Barrero, M. J. Duran, "Recent advances in the design, modeling and control of multiphase machines-Part 1," IEEE Trans. Ind. Electron., vol. 63, no. 3, pp. 449-458, Jan. 2016.

[8] Z. Gao, C. Cecati, S. X. Ding, "A survey of fault diagnosis and faulttolerant techniques-Part 1: fault Diagnosis with model-based and signal-based approaches," IEEE Trans. Indus. Electron., vol. 62, no. 6, pp. 3757-3767, Jun. 2015.

[9] X. Kestelyn, E. Semail, "A vectorial approach for generation of optimal current references for multiphase permanent-magnet synchronous machines in real time," IEEE Trans. Ind. Electron., vol. 58, no. 11, pp. 5057-5065, Nov. 2011.

[10] H. Guzman, M.J. Duran, F. Barrero, B. Bogado, S. Toral, "Speed control of five-phase induction motors with integrated open-phase fault operation using model-based predictive current control techniques," IEEE Trans. Indus. Electron., vol. 61, no. 9, pp. 4474-4484, Sep. 2014.

[11] A. Mohammadpour, L. Parsa, "Global fault-tolerant control technique for multiphase permanent-magnet machines," IEEE Trans. Indus. Appl., vol. 51, no. 1, pp. 178-186, Jan.-Feb. 2015.

[12] L. Bin, S. K. Sharma, "A literature review of IGBT fault diagnostic and protection methods for power inverters," IEEE Trans Indus. Appl., vol. 45, no. 5, pp. 1770-1777, Oct. 2009.

[13] R. A. Hanna, S. Prabhu, "Medium-voltage adjustable-speed drives users' and manufactures' experiences," IEEE Trans. Indus. Appl., vol. 33, no. 6, pp. 1407-1415, Dec. 1997.

[14] B. Mirafzal, "Survey of fault-tolerance techniques for three-phase voltage source inverters," IEEE Trans. Indus. Electron., Vol. 61, no. 10, pp. 5192-5202, Oct. 2014.

[15] B.A. Welchko, T. A. Lipo, T. M. Jahns, S.E. Schulz, "Fault tolerant three-phase ac motor drive topologies: a comparison of features, cost, and limitations," IEEE Trans. Power Electron., vol. 19, no. 4, pp. 11081116, Jul. 2004.

[16] K. Ambusaidi, V. Pickert, B. Zahawi, "New circuit topology for fault tolerant H-bridge DC-DC converter," IEEE Trans. Power Electron., vol. 25, no. 6, pp. 1509-1516, Jun. 2010.

[17] A.E. Ginart, P. W. Kalgren, M. J. Roemer, D.W. Brown, M. Abbas, "Transistor diagnostic strategies and extended operation under onetransistor trigger suppression in inverter power drives," IEEE Trans. Power Electron., vol. 25, no. 2, pp. 499-506, Jun. 2010.

[18] N. K. Nguyen, F. Meinguet, E. Semail, X. Kestelyn, "Fault-tolerant operation of an open-end winding five-phase PMSM drive with shortcircuit inverter fault," IEEE Trans. Indus. Electron., vol. 63, no. 1, pp. 595-605, Jan. 2016. 
[19] H. Guzman, M. J. Duran, F. Barrero, L. Zarri, B. Bogado, I. Gonzalez, Manuel R. Arahal, "Comparative study of predictive and resonant controllers in fault-tolerant five-phase induction motor drives," IEEE Trans. Indus. Electron., vol. 63, no. 1, pp. 606-617, Jan. 2016.

[20] F. Wu, J. Zhao, "A real-time multiple open-circuit fault diagnosis method in voltage-source-inverter fed vector controlled drives," IEEE Trans. Power Electron., vol. 31, no. 2, pp. 1425-1437, Feb. 2016.

[21] S. M. Jung, J. K. Park, H. W. Kim, K. Y.Cho, M. J. Youn, “An MRASbased diagnosis of open-circuit fault in PWM voltage-source inverters for PM synchronous motor drive systems," IEEE Trans. Power Electron., vol. 28, no. 5, pp. 2514-2526, May 2013.

[22] R. L. A. Ribeiro, C. B. Jacobina, E. R. C. da Silva, A. M. N. Lima, "Fault detection of open-switch damage in voltage-fed PWM motor drive systems," IEEE Trans. Power Electron., vol. 18, no. 2, pp. 587593, Mar. 2003.

[23] Q-T An, L-Z Sun, K. Zhao, L. Sun, "Switching function model based fast diagnostic method of open-switch faults in inverters without sensors," IEEE Trans. Power Electron., vol. 26, no. 1, pp. 119-126, Jan. 2011.

[24] M. Trabelsi, M. Boussak, M. Gossa, "PWM-switching pattern-based diagnosis scheme for single and multiple open-switch damages in VSIfed induction motor drives," ISA Trans., vol. 51, pp. 333-344, 2012.

[25] S. Abramik, W. Sleszynski, J. Nieznanski, H. Piquet, "A diagnostic method for on-line fault detection and localization in VSI-fed ac drives," in Proc. EPE, Toulouse, France, 2003, pp. 8.

[26] W. Sleszynski, J. Nieznanski, A. Cichowski, "Open-transistor fault diagnostics in voltage-source inverters by analyzing the load currents," IEEE Trans. Indus. Electron., vol. 56, no. 11, pp. 4681-4688, Nov. 2009.

[27] B. G. Park, K. J. Lee, R. Y. Kim, T. S. Kim, J. S. Ryn, D. S. Hyun, "Simple fault diagnosis based on operating characteristic of brushless direct-current motor drives," IEEE Trans. Indus. Electron., vol. 58, no. 5, pp. 1586-1593, Feb. 2011.

[28] M. S. Khanniche, "Wavelet-fuzzy-based algorithm for condition monitoring of voltage source inverter," Electron. Letter, vol. 40, no. 4, pp. 267-268, Feb. 2004.

[29] J. O. Estima, A. J. Marques Cardoso, "A new algorithm for real-time multiple open-circuit fault diagnosis in voltage-fed PWM motor drives by the reference currents errors," IEEE Trans. Indus. Electron., vol. 28, no. 5, pp. 3496-3505, Aug. 2013.

[30] M. Salehifar, R. S. Arashloo, J. M. Moreno-Equilaz, V. Sala, L. Romeral, "Fault detection and fault tolerant operation of a five phase PM motor drive using adaptative model identification approach," IEEE J. Emerging Sel. Top. Power Electron, vol. 2, no. 2, pp. 212-223, Jun. 2014. 